\title{
Opportunities for European Obesity Research in the Coming Decade - a Perspective from the European Association for the Study of Obesity (EASO)
}

\author{
Jean-Michel Oppert ${ }^{\mathrm{a}}$ Thorkild I.A. Sørensen ${ }^{\mathrm{b}} \quad$ Johannes Hebebrand $^{\mathrm{c}}$ Euan Woodward ${ }^{\mathrm{d}}$ \\ John E. Blundelle \\ ${ }^{a}$ Institute of Cardiometabolic Disease and Nutrition (ICAN), University Pierre et Marie Curie-Paris 6; Department of Nutrition, \\ Pitie-Salpetriere Hospital (AP-HP), Paris, France \\ ${ }^{b}$ Institute of Preventive Medicine, Copenhagen University Hospitals; the Novo Nordisk Foundation Centre for Basic Metabolic Research, \\ Faculty of Health Sciences, University of Copenhagen, Copenhagen, Denmark \\ ${ }^{c}$ Department of Child and Adolescent Psychiatry, University of Duisburg-Essen, Essen, Germany \\ ${ }^{\mathrm{d}}$ European Association for the Study of Obesity (EASO), London, \\ ${ }^{\mathrm{e}}$ Institute of Psychological Sciences, Faculty of Medicine and Health, University of Leeds, Leeds, UK
}

In a recent OBESITY FACTS editorial, the question was asked whether the next EU research Framework Programme would provide 'A New Horizon for European Obesity Research?' [1]. In the present editorial, we would like to emphasise that the landscape of European research in the coming years should indeed be viewed as providing important new opportunities for the obesity research community. We would also like to explain in this context the work currently performed within the EASO (www.easo.org), especially the preparation of a conference in early 2012 on priorities in European obesity research.

According to documents published by the European Commission, the new Framework Programme, Horizon 2020, is built around the concept of Grand Societal Challenges and has three key objectives: excellent science, competitive industries, better society (http://ec.europa.eu/research/horizon 2020). The ambition for Horizon 2020 is 'to maximise the contribution of EU funded research and innovation to sustainable growth and jobs and to tackling the grand challenges facing Europe - for example climate change, energy and food security, health and our ageing population. This will be achieved by creating a coherent set of instruments along the whole 'innovation chain', starting from basic research and culminating in bringing innovative products and services to market, and also by supporting non-technological innovation, for example in design and marketing'.

It is our belief that obesity fits very well into this new vision for European research. It is well established that obesity dis- proportionately affects socio-economically disadvantaged populations and is a heavy burden not only on individuals but also on health care systems and the efficiency of the work force. Curbing the obesity trend requires the development of new forms of social innovation and communication as much as novel medical technologies and drugs [2]. New theories leading to paradigm shifts may be needed. Obesity research represents a large scientific field - from basic molecular science to public health and humanities - where researchers across Europe have been very active over the years and have gained world-wide recognition. However, the scope of the problem clearly calls for increased collaboration and coordination of research activities on obesity across Europe.

One of the aims of EASO is to promote research into obesity and to facilitate contact between individuals and organisations across Europe with the aim to help tackle the epidemic of obesity in our region (see www.easo.org for EASO Strategic Plan). EASO is very well aware of the challenges facing the obesity research community in Europe and is taking actions to ensure that European obesity research is put in a proper position in future scientific policies and programmes. As an umbrella organisation for national associations for the study of obesity established in 32 countries across Europe, EASO is in a unique position to be able to provide views on needs and trends in obesity research throughout Europe.

An important event took place in 2010 when experts from EASO's Scientific Advisory Board (SAB) met to provide a snap-shot review of the current status and effectiveness of

\section{KARGER}

Fax +497614520714

Information@Karger.de

www.karger.com
(C) 2011 S. Karger GmbH, Freiburg

$1662-4025 / 11 / 0046-0425 \$ 38.00 / 0$

Accessible online at:

www.karger.com/ofa
Prof. Dr. Jean-Michel Oppert

Department of Nutrition, Pitié-Salpêtrière Hospital (AP-HP)

83, Boulevard de l'Hôpital, 75013 Paris, France

Tel. +331 42 1779-48, Fax -63

jean-michel.oppert@psl.aphp.fr 
obesity research in Europe which was underpinned by data received from EASO national associations [3]. Key questions were identified such as: 'Is this the time for a serious reconsideration of the value of obesity research?', 'How much more knowledge is needed and in which areas?' and 'Should only translational research be funded?' The entire spectrum of obesity research is so large that many areas could not be covered, but were deemed of deserving further examination. It is now clear that we need to go much further in our efforts to better identify the needs for research in various regions, the capacity of the European research community and the impact of research on the social, psychological, economic and medical issues associated with the obesity epidemic. As a next step, EASO will convene a European obesity research conference in 2012. The meeting will take place in Brussels on February 29, 2012 and will be hosted by DG Research from the European Commission. Prior to this conference, two workshops were organised by obesity researchers at a national level, in Denmark and in Germany. A preparatory meeting of EASO's SAB also took place in November 2011.

The 2012 European obesity research conference will be entitled 'From Biology to Society - What Message Can Obesity Research Deliver to Policy Makers?' The mission of the conference is 'to challenge current thinking in European obesity research in order to identify those priorities that may push our scientific frontier in the field and which may achieve the greatest societal and economic impact in the next decade'. The programme has been built along the three main ideas of importance of societal impact, focus on innovation and establishment of cross-disciplinary research. It will include a series of short, focussed presentations by leading European scientists on cross-sectional topics: i) behaviour change through the lifespan (including ageing, unemployment), ii) prevention and public health (capacity building, physical environments, regulatory measures), iii) management and treatment (biomarkers, personalised medicine, bariatric surgery as a model for research), iv) new avenues in pathogenesis and consequences of obesity (fat storage, food addiction). Then, discussion sessions will allow participants to work in groups to identify major research issues to be presented to the plenary. The essential outcome of the conference will be presented at a brief meeting in the European Parliament the following day.

EASO strongly believes that obesity research offers a unique platform for a large-scale coordinated European research effort based on real cross-disciplinary research, which can deliver social and technological innovation, have a measurable impact on European health systems and, not least, can capture the public interest and imagination and thereby the expectations. It is the ambition of the EASO to invigorate our thinking, to initiate a continuous dialogue with its members and relevant stakeholders and to make propositions on these crucial issues for the future health of European citizens. We hope that the 2012 European obesity research conference will act as a catalyst for the development of actions that will lead to a European research strategy taking into account the challenge of obesity as a priority.

\section{Acknowledgments}

JMO is the President of EASO, JEB is the Treasurer of EASO and Chair of EASO SAB, EW is the Executive Director of EASO, TIAS and JH are members of EASO SAB. We would like to thank all EASO SAB colleagues for their active contribution to projects undertaken by EASO and described in this paper.

\section{References}

1 Andersson M: A new horizon for European obesity research? - a short introduction to the EU's next Framework Programme. Obes Facts 2011;4: $260-262$.
Gortmaker SL, Swinburn BA, Levy D, Carter R, Mabry PL, Finegood DT, Huang T, Marsh T, Moodie ML: Changing the future of obesity: science, policy, and action. Lancet 2011;378:838-847.
Blundell JE, Hebebrand J, Oppert JM: What is the value of obesity research? Obes Facts 2010;3:279282. 